\title{
Frequency of Complete Absence of Suprascapular Notch in Dry Scapulae - An Osteological Study with Clinical Significance
}

\author{
Susmita Saha1, Shilpi Garg², Amit Kumar Saxena ${ }^{3}$
}

1Department of Anatomy, Faculty of Medicine and Health Sciences, SGT University, Budhera, Gurgaon, Haryana, India. ${ }^{2}$ Department of Anatomy, Faculty of Medicine and Health Sciences, SGT University, Budhera, Gurgaon, Haryana, India. ${ }^{3}$ Department of Anatomy, Faculty of Medicine and Health Sciences, SGT University, Budhera, Gurgaon, Haryana, India.

\section{ABSTRACT}

\section{BACKGROUND}

Suprascapular notch is a depression located in the superior border of the scapula near its lateral part, close to the root of the coracoid process. It is bridged by the superior transverse scapular ligament \& serves as a path for the suprascapular nerve. The notch is commonly seen in all the scapulae with variable morphology. Sometimes, it is associated with ossified transverse scapular ligament which plays an important role for the suprascapular neuropathies which has been suggested in many previous literatures. But, its absence can also be a reason for nerve entrapment which has been mentioned less frequently. The purpose of this study was to find out the incidence of completely absent suprascapular notch among dry scapulae of north India, especially Gurugram region along with a morphometric evaluation of superior border of scapular where the notch is situated.

\section{METHODS}

One hundred \& ten adult dry scapulae of unknown sex from the osteology museum of SGT Medical College, Gurugram, were obtained for evaluation of absence of suprascapular notch in the superior border of the scapulae near the root of the coracoid process by subjective evaluation (visual inspection). We have also done a morphometric evaluation (length) of the superior border of all the scapulae irrespective of the suprascapular notch. Our observations were compared with other osteological studies performed on other population groups.

\section{RESULTS}

Of the 110 scapulae studied, 43 belonged to right side \& 67 scapulae of left side. By visual inspection, 13 scapulae $(11.8 \%)$ were devoid of suprascapular notch on the upper border \& rest 88 scapulae (88.81\%) had different variety of suprascapular notch. Among the 13 scapulae without suprascapular notch, 8 scapulae $(61.5 \%)$ were of right side and 5 scapulae (38.46\%) were of left sided bone. Apart from this, the average length of the superior border of the scapulae was $42.73 \mathrm{~mm}$.

\section{CONCLUSIONS}

Incidence of completely absent suprascapular notch in our study is $11.8 \%$ which will act as a reference point among Gurugram population in north India. Clinicians should keep in mind about complete absence of suprascapular notch which can be a probable reason for the suprascapular nerve entrapment.

\section{KEY WORDS}

Scapula, Superior Border, Suprascapular Notch, Absent Suprascapular Notch, Morphology, Entrapment Neuropathy
Corresponding Author:

Dr. Susmita Saha,

Flat No. 8C, pkt 10B, Blk. 7,

Jasola-110025, New Delhi, India.

E-mail: drsusmita.sh@gmail.com

DOI: $10.14260 /$ jemds/2020/43

Financial or Other Competing Interests: None.

How to Cite This Article:

Saha S, Garg S, Saxena AK. Frequency of complete absence of suprascapular notch in dry scapulae- an osteological study with clinical significance. J. Evolution Med. Dent. Sci. 2020;9(04):182-186, DOI: 10.14260/jemds/2020/43

Submission 03-10-2019,

Peer Review 07-01-2020,

Acceptance 14-01-2020,

Published 27-01-2020. 


\section{BACKGROUND}

Scapulae is a triangular flat bone which lies on the posterolateral aspect of the chest wall extending from second to seventh rib and articulates with the clavicle \& the head of the humerus with many soft tissue attachments.(1) Numerous major clinical conditions are related to this bone like impingement syndrome, entrapment neuropathies \& glenohumeral dislocations with disabilities.(1) The bone is also known as shoulder blade; two in either sides of the thoracic wall which link the appendicular skeleton of the upper limb with the axial skeleton with the help of the clavicle.(2) The bone is having a body with 2 surfaces; costal or subscapular fossa and a dorsal surface which is further divided into supraspinous \& infraspinous fossa as it contains a spinous process. It also bears 3 angles, superior; inferior \& lateral which actually possess the glenoid cavity to form the shoulder joint.(2) So, scapula plays an important role in the movements of the glenohumeral joint.(3) Scapula also contains three borders; superior, medial \& lateral. Among the three borders, the superior one is the thinnest \& shortest which extending from the root of the coracoid process to the superior angle of the scapula.(4) The superior border is mostly interrupted by the presence of suprascapular notch near the junction of medial two third \& lateral one third very close to the coracoid process.(5) Normally the suprascapular notch of different variety is located in the lateral part of the superior border.(5,6) Sometimes the notch is bridged by the ossified superior transverse scapular ligament converting the notch into a foramen. ${ }^{(4)}$ The suprascapular nerve arising from the upper trunk of the brachial plexus traverses under the superior transverse scapular ligament to supply the supraspinatus muscle, then runs along the lateral border in the spinoglenoid notch to enter into the infraspinous fossa to innervate the infraspinatus muscle.(4) So, entrapment of the nerve is very common whenever there is ossified superior transverse scapular ligament leading to a foramen \& this condition was first described by Koppel \& Thompson. (7) The morphological variation regarding the suprascapular notch is one of the causative factors for suprascapular neuropathies which is seen mostly in athletes.(8) Most frequent clinical manifestations are inability to abduct the arm not only in athletes but also fencers, dancers, hunters \& individual performing lot of overhead abduction as a part of their occupation. $(9,10,11)$ The most popular classifications for suprascapular notch is the one by Rengachary et al. described in 1979 where six types of suprascapular notches were defined.(12,13) Among the six types, the first variety of scapulae showed small indentation or no notch near the coracoid process of scapula.(12) Ticker et al. categorized the suprascapular notch of scapulae into ' $U$ ' \& ' $V$ ' shaped variety.(13) But, other authors have also described the morphological variations of the notch according to their shape like U shaped; V shaped; foramen or absent notch means totally straight superior border.(14,15,16) Though normally the notch is present in the scapula with various morphological features with many clinical implications, but its absence is also seen in some of the scapulae.(17) So, complete absence of suprascapular notch is also thought to be a reason for nerve entrapment as compression of the suprascapular nerve is possible by the superior transverse scapular ligament characterized by diffuse pain in the posterolateral aspect of the shoulder causing weak abduction.(18) Very few studies have been performed to determine the incidence of absent suprascapular notch in Indian population, so keeping this in mind the study have been undertaken among the dry scapulae of north Indian zone.

\section{METHODS}

In the present anatomical study, 110 adult dry scapulae (this was the sample size available in the department; was more than 30 which is the minimum no for the sample size in any osteological study) of unknown sex obtained from the osteology museum of Department of Anatomy, SGT Medical College, Gurugram were evaluated for the incidence of absent suprascapular notch. Scapulae were segregated \& broken scapulae especially the superior border was excluded for the evaluation. General morphological parameter like the side of the bone was also mentioned. Each bone was studied for the presence or absence of any types of notch in the superior border near the root of the coracoid process like U shaped; $V$ shaped, ossified suprascapular ligament which convert the notch into foramen by subjective evaluation (visual inspection). Then the incidence of completely absent suprascapular notch was calculated according to the side of the scapulae. Apart from this, we have also measured the length of the superior border of all the scapulae irrespective to the presence or absence of notch by a digital vernier caliper in mm which extends from the root of the coracoid process to the superior angle of the scapula. Scapulae with absent suprascapular notch were segregated for photography \& proper documentation was done. We have also done photography for ' $U$ ' shaped notch \& scapula with suprascapular foramen for the differentiation of absent notch in the superior border.

\section{Statistical Analysis}

All the data obtained were tabulated in Microsoft excel 2007 version \& maximum; minimum; mean \& standard deviation was calculated. Though it was a descriptive type of analysis, so test of significance was not applied.

\section{RESULTS}

In the present osteological evaluation, 110 adult dry intact scapulae were examined for the incidence of absent suprascapular notch on the superior border of the scapulae by visual inspection. Out of the 110 scapulae studied, 43 belonged to right side and 67 belonged to left side. By subjective evaluation (visual inspection) method we have obtained 13 scapulae (11.8\%) were devoid of suprascapular notch on the superior border of scapulae; rest 88 scapulae $(88.81 \%)$ with different types of notches like little indentation, U shaped, $\mathrm{V}$ shaped or suprascapular foramen on the superior border of scapulae which has been displayed in the Table along with the graphical representation in Table. It was also observed that, among the 13 scapulae with absent suprascapular notch, 8 scapulae (61.5\%) were belonged to the right side \& 5 scapulae (38.46\%) were of the left side. The 
incidence of morphological evaluation of absence suprascapular notch according to the side has been displayed in Table 1 . Among all the dry specimens where suprascapular notch was absent, it was observed that there was no lateral confluent near the root of the coracoid process thus to confirm its absence. Mostly the superior border was straight in our observation among the scapulae with absent suprascapular notch.

\begin{tabular}{|c|c|c|c|}
\hline $\begin{array}{c}\text { Side of the } \\
\text { Scapulae }\end{array}$ & $\begin{array}{c}\text { No. of Bones without } \\
\text { Notch n (\%) }\end{array}$ & $\begin{array}{c}\text { No. of Bones with } \\
\text { Notch N (\%) }\end{array}$ & Total n \\
\hline Right & $8(61.5 \%)$ & $35(36.08 \%)$ & $43(39.09 \%)$ \\
\hline Left & $5(38.4 \%)$ & $62(63.91 \%)$ & $67(60.9 \%)$ \\
\hline Total & $\mathbf{1 3 ( 1 1 . 8 \% )}$ & $\mathbf{9 7 ( 8 8 . 1 8 \% )}$ & 110 \\
\hline Table 1. The Incidence of Morphological Evaluation of Absence of \\
Suprascapular Notch According to the Side \\
\hline
\end{tabular}

Along with this, the morphometric evaluation (Length) of the superior border of all scapulae was also measured. We observed the mean length of superior border of scapula was $57.83 \mathrm{~mm}$ irrespective to the side or presence or absence of the notch. The minimum, maximum, mean and standard deviation of the length is shown in Table 2. Though the results are of descriptive statistics type, so application of test for significance was not required.

\begin{tabular}{|c|c|c|c|c|c|}
\hline $\begin{array}{c}\text { Total No. of } \\
\text { Scapulae (n) }\end{array}$ & $\begin{array}{c}\text { Parameters } \\
\text { Measured }\end{array}$ & $\begin{array}{c}\text { Maximum } \\
(\mathbf{m m})\end{array}$ & $\begin{array}{c}\text { Minimum } \\
(\mathbf{m m})\end{array}$ & $\begin{array}{c}\text { Mean } \\
(\mathbf{m m})\end{array}$ & $\begin{array}{c}\text { Std. } \\
\text { Deviation }\end{array}$ \\
\hline 110 & $\begin{array}{c}\text { Length of superior } \\
\text { border of scapula }\end{array}$ & 57.83 & 30.18 & 42.73 & 5.5501 \\
\hline Table 2. Morphometric Parameters (Length) of Superior Border of the \\
Scapula \\
\hline
\end{tabular}

\section{DISCUSSION}

The suprascapular notch is very commonly seen in the superior border of almost all scapulae at its anterolateral end separating the superior border from the root of the coracoid process. ${ }^{(1,2)}$ The notch is bridged by the superior transverse scapular ligament which extends from the medial end of the notch up to the root of the coracoid process converting it into a foramen.(2) Though the notch shows variable morphological features but it acts as a common cause for the entrapment neuropathy because it transmits suprascapular nerve to enter into the supraspinous fossa.(2) Its position is an important anatomical landmark for the suprascapular nerve during different arthroscopic surgical procedure in relation to glenohumeral joint.(19) So, this morphological feature clinically plays a major role like other parts of the scapula which becomes a area of choice for osteological investigations by the researchers. The suprascapular nerve is a large branch coming from the upper trunk of the brachial plexus follows an oblique course through the posterior cervical triangle to go towards the suprascapular notch.(2,20) Movements like overhead abduction of the shoulder joint can result traction force on the suprascapular nerve leading to its compression against the upper border.(20) Rengachary et al. in 1979, had described six different types of suprascapular notches which was one of the most popular classification regarding variable morphology of suprascapular notch.(12,13) In his classification, type I was the category for the absent suprascapular notch among the scapulae. The risk of entrapment neuropathy increases in many folds when absent suprascapular notch seen along with the ossified superior tranverse scapular ligament. $(2,20,21)$ Many authors have followed Rengacharry's classification for the morphological variations of suprascapular notch as well as for the incidence of ossified superior transverse scapular ligament converting the notch into foramen.(12) Some of the authors Vedha et al., Kour et al., Fatima et al. also described suprascapular notch according to different alphabetical symbol like shallow $U$, deep $U, V$ shaped, J shaped \& slightly indented notch among Indian population. $(14,15,16)$ Wang et al. described the notch by measuring different diameters like vertical \& transverse; to classify the different variety of notches.(22) Several authors have also reported about variations such as calcification, bifurcation or trifurcation \& hypertrophy of transverse scapular ligament which was also a directly associated with entrapment neuropathy. $(23,24,25)$ But incidence of complete absence of suprascapular notch with clinical implications was mentioned in very few studies which have been displayed in Table $3 \& 4$.

\begin{tabular}{|c|c|c|c|c|}
\hline Authors & Year & $\begin{array}{c}\text { Population } \\
\text { Group }\end{array}$ & $\begin{array}{c}\text { No. of } \\
\text { Scapulae }\end{array}$ & $\begin{array}{c}\text { Incidence of Absent } \\
\text { Suprascapular Notch (\%) }\end{array}$ \\
\hline $\begin{array}{c}\text { Rengachary et } \\
\text { al.(12) }\end{array}$ & 1979 & American & 211 & 8 \\
\hline Natsis et al.(26) & 2007 & Greek & 423 & 6 \\
\hline Ofusori et al.(6) & 2008 & Nigerian & & Single Case Report \\
\hline Sinkeet et al.(27) & 2010 & Kenyan & 138 & 22 \\
\hline Iqbal et al.(28) & 2010 & Rawalpindi & 250 & 18 \\
\hline Wang et al.(22) & 2011 & Chinese & 295 & 28 \\
\hline Polgus et al.(29) & 2013 & Poland & 81 & 6 \\
\hline Albino et al.(30) & 2013 & Italian & 500 & 12.4 \\
\hline Present study & 2019 & India & 110 & 11.8 \\
\hline
\end{tabular}

Table 3. Meta-Analysis of the Incidence of Absent Suprascapular Notch in the Scapula among Different Population Groups

In few of the studies, authors like Ofusori et al. \& Rekha et al. have mentioned about single case regarding the incidence of absence suprascapular notch in Nigerian and Indian population respectively. ${ }^{(6,18)}$ They suggested that, the absence of suprascapular notch is a possible reason of compression of the suprascapular nerve by the superior transverse ligament on the upper border of the scapula which can be pronounced if the ligament becomes ossified. This can further lead to paralysis, weakness, numbness etc as well as weakness while abduction of the shoulder joint causing disability in shoulder movements. ${ }^{(6,18)}$ So, this type of morphological variations play great role for the nerve entrapment because its injury can cause severe rotator cuff dysfunction. The incidence of complete absence of suprascapular notch in our study is almost similar studies performed by Kour et al., Varghese et al., Mahato et al., Vaidya et al. among Indian population though sample size as well as regional variation still present.(15,31,32,33) Apart from this, our observation for the incidence was almost similar with work done by Albino et al. in Italian population but the sample size was very high in their case.(30) Similar results for the incidence were seen in studied performed by Natsis et al. \& Polgus et al. among population of Greek \& Poland.(26,29) Their result was also similar with the research performed by Pragna et al., Kour et al., Varghese et al. among Indian population.(34,15,32) It was observed that, except researches done by Rubi et al., Rekha et al. \& Jawed et al. where only incidence of absent suprascapular notch was reported,(17,18,35) rest of the studies by other authors were performed to determine the incidence of all the morphological variations of suprascapular notch 
among Indian population including absent suprascapular notch in dry scapulae.

\begin{tabular}{|c|c|c|c|c|}
\hline Authors & Year & $\begin{array}{c}\text { Population } \\
\text { (Different } \\
\text { Regions in India) }\end{array}$ & $\begin{array}{c}\text { No. of } \\
\text { Scapulae }\end{array}$ & $\begin{array}{c}\text { Incidence of } \\
\text { Absent } \\
\text { Suprascapular } \\
\text { Notch (\%) }\end{array}$ \\
\hline Soni et al.(36) & 2012 & Agroha & 100 & $2 \%$ \\
\hline Rekha et al.(18) & 2013 & Karnataka & \multicolumn{2}{|c|}{ Single Case Report } \\
\hline Vasudha et al.(37) & 2013 & Karnataka & 115 & $6 \%$ \\
\hline Reddy et al..(38) & 2013 & Andhra Pradesh & 104 & $21.15 \%$ \\
\hline Pragna et al.(34) & 2013 & Gujarat & 80 & $6.25 \%$ \\
\hline Jawed et al.(35) & 2014 & Patna & 220 & $34(15.46 \%)$ \\
\hline Kannan et al.(39) & 2014 & Pondicherry & 415 & $80(20 \%)$ \\
\hline Desai et al.(40) & 2014 & Gujarat & 200 & $16 \%$ \\
\hline Kour et al.(15) & 2016 & Jammu & 60 & $8(13.3 \%)$ \\
\hline Rubi et al.(17) & 2016 & Assam & 236 & $42(17.79 \%)$ \\
\hline Varghese et al.(32) & 2017 & Kerala & 50 & $7(14 \%)$ \\
\hline Mahato et al.(31) & 2017 & Tamil Nadu & 250 & $23(9.2 \%)$ \\
\hline Vaidya et al.(33) & 2018 & Uttar Pradesh & 140 & $13(9.28 \%)$ \\
\hline Present study & 2019 & Gurugram & 110 & $13(11.8 \%)$ \\
\hline Table 4. Comparative Analysis of Incidence of Scapulae without \\
Suprascapular Notch among Populations of Different Regions in India
\end{tabular}

Scapula is an interesting bone for the researchers regarding different morphometrical investigations as to help the surgeons to perform surgical procedure. So, we have measured the length of superior border of all the scapulae which was 42.37 in average expecting a normal baseline data for the population of North India. In studies done by Rekha et al. \& Ofusori et al. it was almost same around $6 \mathrm{~cm}$ which was different from our study, but both were measured in a single bone among South Indian \& Nigerian population respectably. $(6,18)$

\begin{tabular}{|c|c|c|c|c|}
\hline Authors & Year & $\begin{array}{c}\text { Population } \\
\text { (Different } \\
\text { Regions in India) }\end{array}$ & $\begin{array}{c}\text { No. of } \\
\text { Scapulae }\end{array}$ & $\begin{array}{c}\text { Length of the } \\
\text { Superior Border } \\
\text { of Scapula }\end{array}$ \\
\hline Ofusori et al.(${ }^{(6)}$ & 2008 & Nigerian & Single case report & $6.5 \mathrm{~cm}$ \\
\hline Rekha et al. ${ }^{(18)}$ & 2013 & Indian & Single case report & $6 \mathrm{~cm}$ \\
\hline Present study & 2019 & Indian & 110 & $42.37 \mathrm{~mm}$ \\
\hline \multicolumn{5}{|c|}{ Table 5. Morphometric Analysis (Length) of the Superior Border of } \\
Scapulae Performed in Other Studies \\
\hline
\end{tabular}

\section{CONCLUSIONS}

Suprascapular notch shows remarkable variations in the scapula which has been reported by many authors among different population groups with different sample sizes. But, very few studies have been undertaken to evaluate the frequency of complete absence of suprascapular notch among Indian population especially north zone. Complete absence of suprascapular notch is an important cause of suprascapular nerve entrapment syndrome. Apart from this, morphological data regarding completely absent suprascapular notch will provide an anatomical baseline to correlate the radiologic findings with clinical presentations which is expected to be of great help to the orthopaedic surgeon to devise appropriate surgical interventions to restore the normal function of the shoulder joint.

\section{ACKNOWLEDGEMENT}

The authors thank Dr. Neelam Vasudeva, Director Professor, Department of Anatomy, Maulana Azad Medical College, for her constant inspiration.

\section{REFERENCES}

[1] Von Schroeder HP, Kuiper SD, Botte MJ. Osseous anatomy of the scapula. Clinical Orthopaedic and Related Reseach 2001;(383):131-9.

[2] Standring S, Ellis H, Healy J, et al. Pectoral girdle, shoulder region \& axilla. Gray's anatomy - the anatomical basis of clinical practice. 39th edn. New York: Elsevier Churchill Livingstone 2005: p. 821-2.

[3] Bardeen CR. Studies on the development of the human Skeleton. American Journal of anatomy 1905;4(3):265302.

[4] Mc Minn RMH. Last's Anatomy. 9th edn. UK edition: Churchill Livingstone 2009: p. 53.

[5] Moore KL, Dalley AF. Clinical oriented anatomy. $5^{\text {th }}$ edn. Williams \& Wilkins Lippincott 2006: p. 730-2.

[6] Ofusori DA, Ude RA, Okwuonu CU, et al. Complete absence of the suprascapular notch in a Nigerian scapula: a possible cause of suprascapular nerve entrapment. Int J Shoulder Surg 2008;2(4):85-6.

[7] Kopell HP, Thompson WA. Pain and the frozen shoulder. Surg Gynecol Obstet 1959;109(1):92-6.

[8] Bayramoglu A, Demiryurek D, Tuccar E, et al. Variations in anatomy of suprascapular notch possibly causing suprascapular nerve entrapment: an anatomical study. Knee Sug Sport Trauma Arthrosc 2003;11(6):393-8.

[9] Cummins CA, Messer TM, Nuber GW. Suprascapular nerve entrapment. J Bone Joint Surg Am 2000;82(3):41524.

[10] Antonoiou J, Tae SK, William GR, et al. Suprascapular neuropathy. Variability in the diagnosis, treatment and outcome. Clin Orthop Rel Res 2001;(386):131- 8.

[11] Vastamaki M, Goransson H. Suprascapular nerve entrapment. Clin Orthop Rel Res 1993;(297):135-43.

[12] Rengachary SS, Neff JP, Singer PA, et al. Suprascapular entrapment neuropathy: a clinical, anatomical and comparative study. Part 1: clinical study. Neurosurg 1979;5(4):441-6.

[13] Rengachary SS, Burr D, Lucas S, et al. Suprascapular entrapment neuropathy: a clinical, anatomical and comparative study. Part 2 - anatomical study. Neurosurg 1979;5(4):447-51.

[14] Fatima N, Rahman S, Kumar B. A morphological study of suprascapular notch in population of Bihar. Ann Int Med Den Res 2017;3(4):AT01-AT05.

[15] Kour M, Gupta S. Morphology of suprascapular notch of scapula \& its clinical implications. JK Science 2016;18(1):31-4.

[16] Vedha S, Vidhulatha K. A morphological study of suprascapular notch and incidence of ossification of superior transverse scapular ligament in south Indian dry scapulae. Int J Curr Res Rev 2017;9(13):45-9.

[17] Saikia R, Deka B, Baishya RJ. A study on complete absence of the suprascapular notch in the population of Assam. Indian Journal of Basic and Applied Medical Research 2016;6(1):750-6.

[18] Rekha BS. Complete absence of suprascapular notch- a case report. Journal of Evolution of Medical and Dental Sciences 2013;2(1):19-22.

[19] Bigliani LU, Dalsey RM, McCann PD, et al. An anatomical study of suprascapular nerve. Arthroscopy 1990;6(4):301-5. 
[20] Poberajj B, Kovacic L. The presence of suprascapular neuropathy in rotator cuff tears. International $\mathrm{J}$ of Shoulder Surgery 2007;1:58-63.

[21] Callahan JD, Scully TB, Shapiro SA, et al. Suprascapular nerve entrapment. A series of 27 cases. J Neurosurg 1991;74(6):893-6.

[22] Wang HJ, Chen C, Wu LP, et al. Variable morphology of the suprascapular notch: an investigation and quantitative measurements in Chinese population. Clin Anat 2011;24(1):47-55.

[23] Ticker JB, Djurasovic M, Strauch RJ, et al. The incidence of ganglion cysts and other variations in anatomy along the course of suprascapular nerve. J Shoulder Elbow Surg 1998;7(5):472-8.

[24] Cohen SB, Dines DM, Moorman CT. Familiar calcification of the superior transverse scapular ligament causing neuropathy. Clin Orthop Relat Res 1997;(334):131-5.

[25] Gracia G, McQueen D. Bilateral suprascapular nerve entrapment syndrome. Case report \& review of the literature. J Bone and Joint Surg 1981;63(3):491-2.

[26] Natsis K, Totlis T, Tsikaras P, et al. Proposal for classification of the suprascapular notch: a study on 423 dried scapulas. Clin Anat 2007;20(2):135-9.

[27] Sinkeet SR, Awori KO, Odula PO, et al. The suprascapular notch: Its morphology and distance from the glenoid cavity in a Kenyan population. Folia Morphol 2010;69(4):241-5.

[28] Iqbal K, Iqbal R, Khan SG. Anatomical variations in shape of suprascapular notch of scapula. J Morphol Sci 2010;27(1):1-2.

[29] Polguj M, Sibinski M, Grzegorzewski A, et al. Morphological and radiological study of ossified superior transverse scapular ligament as potential risk factor of suprascapular nerve entrapment. Biomed Res Int 2014;2014:613601.

[30] Albino P, Carbone S, Candela V, et al. Morphometry of the suprascapular notch: correlation with scapular dimensions and clinical relevance. BMC Musculoskelet Disord 2013;14:172.
[31] Mahato RK, Suman P. Ossification of superior transverse scapular ligament: incidence, etiological factors and clinical relevance. Int J Health Sci Res 2013;3(9):14-21.

[32] Varghese S, Amma MMC. Morphometric study of dry human scapulae. J Evolution Med \& Dent Sci 2017;6(75):5365-5371.

[33] Vaidya KV, Srivastava G, Munsif T, et al. The morphological and morphometric study of suprascapular notch and its variations. EJMR 2018;5(1):1-6.

[34] Patel P, Patel SV, Patel SM, et al. Study of variation in the shape of the suprascapular notch in dried human scapula. Int J Bio Med Res 2013;4(2):3162-4.

[35] Akhtar J, Madhukar PK. A study on complete absence of the suprascapular notch. International J Science \& Research 2014;3(11):411- 5.

[36] Soni G, Malik V, Shukla L, et al. Morphometric analysis of the suprascapular notch. Internet J Biol Anthropol 2012;5(1):20-7.

[37] Vasudha TK, Shetty A, Gowd S, et al. Morphological study on suorascapular notch and superior transeverse scapular ligaments in human scapulae. J Med Res Health Sci 2013;2(4):793-8.

[38] Sangam MR, Devi SSS, Krupadanam K, et al. A study on the morphology of the suprascapular notch and its distance from the Glenoid cavity. J Clin Diagn Res 2013;7(2):189-92.

[39] Kannan U, Kannan NS, Anbalagan J, et al. Study of suprascapular notch in Indian dry scapulae with specific reference to the incidence of completely ossified superior transverse scapular ligament. J Clin Diagn Res 2014;8(3):7-10.

[40] Desai RR, Ambali MP, Doshi MA. Incidence of ossification of superior transverse scapular ligament of scapula in Indian population. Int J Curr Microbiol App Sci 2014;3(9):1080-4. 